\title{
Mutations in NFKB2 and potential genetic heterogeneity in patients with DAVID syndrome, having variable endocrine and immune deficiencies
}

Thierry Brue ${ }^{1,2^{*}}$, Marie-Hélène Quentien ${ }^{1,2}$, Konstantin Khetchoumian ${ }^{3}$, Marco Bensa ${ }^{4}$, José-Mario Capo-Chichi ${ }^{5}$, Brigitte Delemer ${ }^{6}$, Aurelio Balsalobre ${ }^{3}$, Christina Nassif $^{5}$, Dimitris T Papadimitriou ${ }^{7}$, Anne Pagnier ${ }^{8}$,

Caroline Hasselmann ${ }^{5}$, Lysanne Patry ${ }^{5}$, Jeremy Schwartzentruber ${ }^{9}$, Pierre-François Souchon ${ }^{6}$, Shinobu Takayasu ${ }^{3}$, Alain Enjalbert ${ }^{1,2}$, Guy Van Vliet ${ }^{10}$, Jacek Majewski ${ }^{9}$, Jacques Drouin ${ }^{3}$ and Mark E Samuels ${ }^{5,11}$

\footnotetext{
Abstract

Background: DAVID syndrome is a rare condition combining anterior pituitary hormone deficiency with common variable immunodeficiency. NFKB2 mutations have recently been identified in patients with ACTH and variable immunodeficiency. A similar mutation was previously found in Nfkb2 in the immunodeficient Lym1 mouse strain, but the effect of the mutation on endocrine function was not evaluated.

Methods: We ascertained six unrelated DAVID syndrome families. We performed whole exome and traditional Sanger sequencing to search for causal genes. Lym 1 mice were examined for endocrine developmental anomalies.

Results: Mutations in the NFKB2 gene were identified in three of our families through whole exome sequencing, and in a fourth by direct Sanger sequencing. De novo origin of the mutations could be demonstrated in three of the families. All mutations lie near the C-terminus of the protein-coding region, near signals required for processing of NFKB2 protein by the alternative pathway. Two of the probands had anatomical pituitary anomalies, and one had growth and thyroid hormone as well as ACTH deficiency; these findings have not been previously reported. Two children of one of the probands carried the mutation and have to date exhibited only an immune phenotype. No mutations were found near the C-terminus of NFKB2 in the remaining two probands; whole exome sequencing has been performed for one of these. Lym1 mice, carrying a similar Nfkb2 C-terminal mutation, showed normal pituitary anatomy and expression of proopiomelanocortin (POMC).

(Continued on next page)
}

\footnotetext{
* Correspondence: Thierry.BRUE@ap-hm.fr

${ }^{1}$ Aix-Marseille University, Centre de Recherche en Neurobiologie et

Neurophysiologie de Marseille (CRN2M), Centre National de la Recherche

Scientifique, Unité Mixte de Recherche 7286, Faculté de Médecine de

Marseille, 13344 Marseille, France

${ }^{2}$ Assistance Publique-Hôpitaux de Marseille (APHM), Department of Endocrinology, Centre de Référence des Maladies Rares d'Origine

Hypophysaire, Hôpital de la Timone, 13005 Marseille, France

Full list of author information is available at the end of the article
} 
(Continued from previous page)

Conclusions: We confirm previous findings that mutations near the C-terminus of NFKB2 cause combined endocrine and immunodeficiencies. De novo status of the mutations was confirmed in all cases for which both parents were available. The mutations are consistent with a dominant gain-of-function effect, generating an unprocessed NFKB2 super-repressor protein. We expand the potential phenotype of such NFKB2 mutations to include additional pituitary hormone deficiencies as well as anatomical pituitary anomalies. The lack of an observable endocrine phenotype in Lym 1 mice suggests that the endocrine component of DAVID syndrome is either not due to a direct role of NFKB pathways on pituitary development, or else that human and mouse pituitary development differ in its requirements for NFKB pathway function.

\section{Background}

Deficit in anterior pituitary function (hypopituitarism) and common variable immune deficiency (CVID, MIM [607594]) represent two very different clinical presentations. Mutations in several genes have been associated with each of these conditions, but until recently no gene has been associated with deficiencies in both systems in the same patients. Several years ago we identified such patients in three families as part of a national screen for hypopituitarism in France, and defined a novel disorder which we named DAVID syndrome (for Deficient Anterior pituitary with Variable Immune Deficiency) [1]. At the time it was not obvious whether these patients represented a shared molecular etiology or a coincidental overlap of two otherwise uncommon pediatric conditions, although there were at least two previous isolated case reports with similar clinical descriptions [2,3]. Chen et al recently reported mutations in the NFKB2 gene in two families from Utah with features consistent with our definition of DAVID syndrome (immunodeficiency with hypogammaglobulinemia, plus central pituitary deficiency), one mutation of which was consistent with de novo germ line origin [4]. Several additional groups have since reported mutations near the C-terminus of NFKB2, in patients with features overlapping DAVID syndrome, although not all patients showed the endocrine aspect of the phenotype [5-7].

\section{Methods}

Research ethics approval was obtained from the review boards of the Centre de Recherche du CHU Ste-Justine, and of the Assistance Publique-Hôpitaux de Marseille. Written informed consent for the study and for publication of the patients' anonymous details and images were obtained from the participants or their parents. Clinical studies were performed as described in the Additional file 1. All experimental procedures with laboratory animals were approved by the IRCM Animal Protection Committee and followed guidelines and regulations of the Canadian Council of Animal Care. Whole exome sequencing on DNA from peripheral blood leukocytes was performed using standard methods and as previously described (see Additional file 1 for additional details) [8]. PCR-based Sanger sequencing with fluorescent capillary electrophoresis was performed using standard methods, and results were visualized using Mutation Surveyor (Soft Genetics, Inc.) Numbering in this study refers to Refseq entry NM_001077494.3, equivalent to isoform a, consistent with the usual amino acid numbering in functional studies of NFKB2 protein and the noncanonical processing pathway. Nucleotide numbering for mutations begins at the first $\mathrm{A}$ of the initiating methionine ATG.

Lym1 mice were obtained from the Walter and Eliza Hall Institute (Victoria, Australia). Histology and immunohistochemistry were performed as previously described [9]. See Additional file 1 for additional details.

\section{Results and discussion}

Our original French probands, recruited from different geographic regions through the "Genhypopit" network, [10] were noted to have immunodeficiencies of varying severity with recurrent childhood infections and hypogammaglobulinemia, in addition to ACTH deficiency (patients A1, B1, C1, C2, see Figure 1, our original publication for full clinical details, and Additional file 1 for updated phenotypes; $\mathrm{C} 2$ was deceased prior to this study) [1]. Patients A2, A3 and C3 had immune but not endocrine deficiencies. Patient $\mathrm{C} 1$ also had a growth hormone deficiency, and this patient has since developed central (i.e. not thyroidal) hypothyroidism. The endocrine deficiencies appear to be longstanding, not acute secondary to current infections. MRI scans of the pituitary were performed for the probands, with hypoplasia observed for patient B1 but not A1 or C1 (Additional file 1: Figure S1A, B, C1, 2). Since the original report, two new carriers were ascertained in family A, A5 and A6 (see below and Additional file 1: Table S1 for clinical details).

We performed whole exome sequencing on DNA from $\mathrm{A} 1, \mathrm{~B} 1$ and $\mathrm{C} 1$. In the exome data, only one gene carried a rare, protein-altering variant in all three probands, the gene NFKB2 (MIM [164012]). In NFKB2, proband A1 was heterozygous for missense mutation p.A867V, proband B1 was heterozygous for missense mutation p.D865G, and proband $\mathrm{C} 1$ was heterozygous for an $8 \mathrm{bp}$ frameshift deletion, p.R853Afs*29 (Figure 1A, B, C). All three mutations 
A

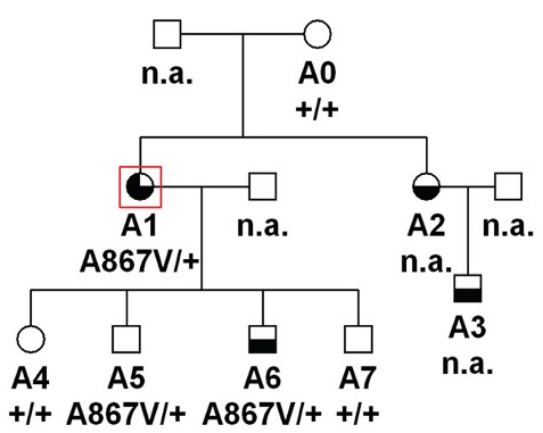

C

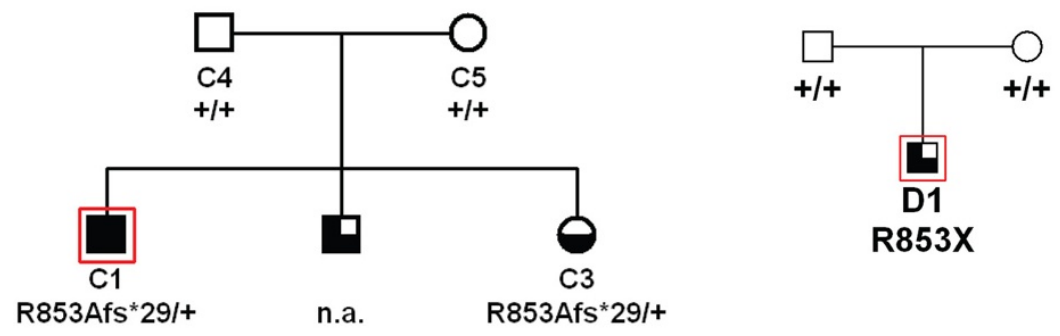

B

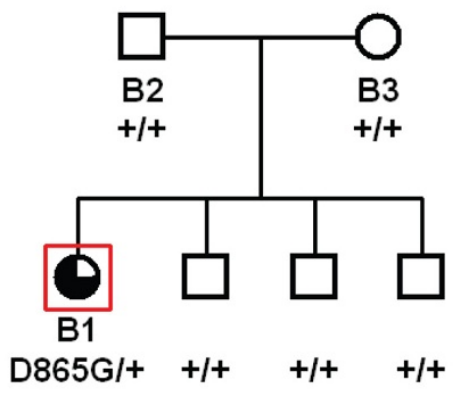

D

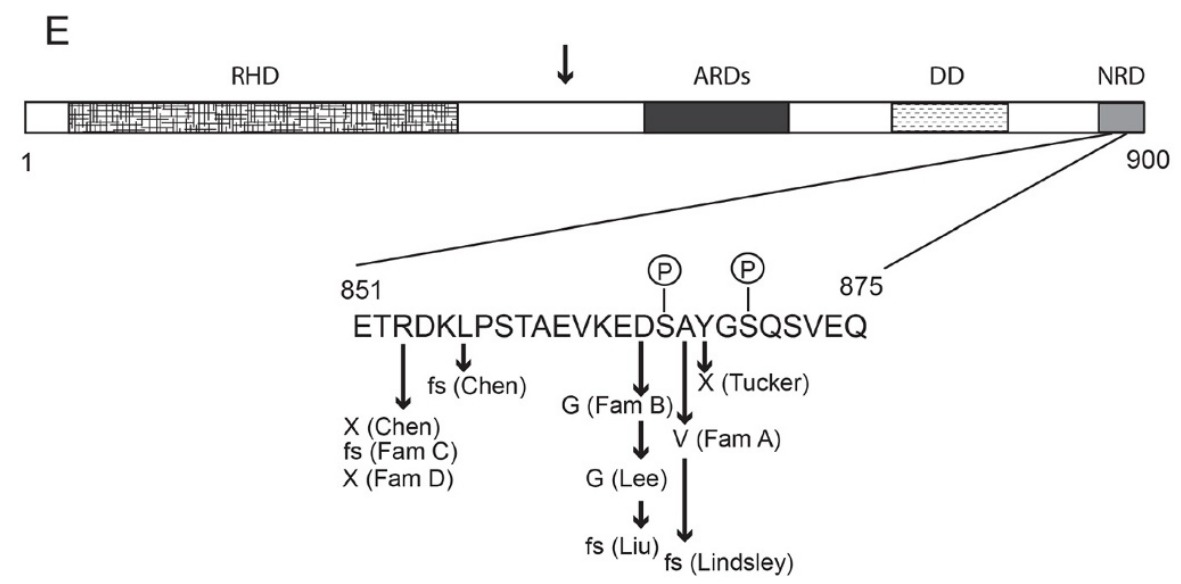

Figure 1 DAVID syndrome families and NFKB2 gene structure with mutations. A-D, pedigrees showing genotypes of sequenced individuals. Symbols: Filled, immunodeficiency, ACTH deficiency, GH deficiency; lower half filled, immunodeficiency; lower half plus upper left quadrant filled, immunodeficiency, ACTH deficiency; open, unaffected or unknown. n.a. DNA and clinical information not available. +/+, no mutation at any of the three sites found in the families. $\mathbf{E}$, structure of the NFKB2 protein (isoform A numbering), indicating the major functional domains, regulated phosphorylated serines 866 and 870, and sites of mutations reported here, by Chen, Liu, Lee, Lindsley et al, or at the orthologous site in the Lym 1 mouse (Tucker et al). The vertical arrow above the domain cartoon indicates approximate site of proteolytic cleavage of p100, which releases the amino-terminal p52 active fragment. RHD, rel homology domain; ARDs, ankyrin repeat domains; DD, death domain; NRD, NIK response domain.

were verified by PCR-based Sanger fluorescent sequencing (Additional file 1: Figure S3A-E). Sequencing confirmed that both parents were negative in peripheral blood DNA for the mutations found in the probands in families B and $\mathrm{C}$, as was the one sampled parent in family A. In families $A$ and $B$, all of the sampled unaffected relatives were negative for the familial mutation (data not shown). Two children of A1, A5 and A6, were heterozygous for the familial mutation (data not shown). One child (A6) showed a clinical phenotype with recurrent infections and immunodeficiency, while A5 had moderate immunoglobulin deficiency with no clinical signs as yet. In family $C$, 
affected sibling C3 of the proband also carried the familial mutation. No additional pathogenic variants were found in any of the probands in targeted exons of genes otherwise known to cause hypopituitarism (see Additional file 1). There were rare protein-altering variants detected in several other genes associated with common variable or severe immunodeficiency, some in $\mathrm{B} 1$ and some in $\mathrm{C} 1$, but none in any two probands together (see Additional file 1: Table S2).

A fourth patient with DAVID syndrome was independently ascertained, previously only reported in abstract form [11]. This patient (D1, see Figure 1, Additional file 1: S2)) was asthenic with immunodeficiency from an early age, suffered hair loss and onychodystrophy, and had low ACTH before and after CRH stimulation. All other pituitary functions were normal, and MRI showed hypoplastic anterior pituitary (Additional file 1: Figure S1D, see Additional file 1 for more details). The two C-terminal coding exons of NFKB2 were directly sequenced in DNA from patient D1, using PCR-based Sanger technology. The patient was heterozygous for a truncating mutation also at amino acid position 853, p.R253X (Figure 1D). This was not the same as the frameshift mutation at the same residue in family $\mathrm{C}$. The mutation was not present in blood DNA from either parent (data not shown).

All variants have been submitted to ClinVar and assigned preliminary accession numbers pending database curation: c.2556_2563del SCV000172085; c.2594A > G SCV0001720 86; c. $2600 \mathrm{C}>\mathrm{T}$ SCV000172087; c. $2557 \mathrm{C}>\mathrm{T}$ SCV00017 2088.

Our genetic findings strongly implicate NFKB2 as the causal gene for DAVID syndrome in our patients, particularly taking into account similar mutations found by two other groups in similar patients. In all we identified four different heterozygous mutations, two protein-truncating and two missense variants, near the $\mathrm{C}$-terminus of the protein coding region of $N F K B 2$, a region required for the correct processing of the primary translation product (Figure $1 \mathrm{E}$ ) $[12,13]$. In the three families $(B, C, D)$ where both parents could be sampled, neither parent carried the mutation in DNA from peripheral lymphocytes, consistent with the mutations being germline de novo; family A with only one parent available is also compatible with this model of transmission. The occurrence of two affected siblings in family $\mathrm{C}$ is completely consistent with the proposed de novo germ line origin of the mutations. Although uncommon, such mutations may arise in mitotic germ line clones, either in testes or ovaries, and clonally expand, giving rise to mutation-carrying post-meiotic gametes repeatedly, potentially over a period of years. Intrafamilial recurrence in multiple affected siblings with presumptive de novo pre-meiotic germ line origin has been reported in numerous studies of unrelated genetic disorders [14-18].

The mutation in family $\mathrm{B}$ of Chen et al is identical to the mutation in our family $\mathrm{D}$ at the nucleotide and protein level (p.R253X, Figure 1E) [4]. These probably represent independent mutational events, although the ethnicity of their family was not reported. In the family reported by Liu et al., the phenotype co-segregates with a frameshift mutation beginning one amino acid upstream of phosphorylated serine 865 . It should be noted that hypoplastic pituitary anatomy as visualized by MRI was not reported by either Chen or Liu et al, whereas two of our patients have anatomical pituitary defects. Similarly, the mutation p.D865G reported by Lee $e t a l$ is the same as that found in our family B [5]. Lee et al demonstrated that this mutation deleteriously affected NFKB2 protein processing in response to activation of the non-canonical pathway. Oddly, all three patients of Lee $e t a l$ are reported to have alopecia areata, which we did not observe in our patient B1, whereas their patients lacked an overt endocrine deficiency.

The unique association of ACTH deficiency with combined variable immunodeficiency in DAVID syndrome suggested that NFKB2 might have a critical role in pituitary development, particularly for differentiation of ACTHproducing corticotrope cells. A similar mutation near the C-terminus of the murine $N f k b 2$ ortholog was previously identified in a large scale mouse mutagenesis screen for cellular immunodeficiency [19]. This Lym1 strain shows severely reduced viability as homozygotes, although heterozygotes are viable and fertile. The mice show multiple aspects of immunodeficiency similar to DAVID syndrome, including a reduced $\mathrm{B}$ cell compartment and reduced antigen response with hypogammaglobulinemia and autoimmune response in heterozygotes. However the endocrine status of these mice was not previously described, nor was the anatomical development of their hypothalamus and pituitary. We assessed pituitary development in the Lym1 mice at various ages. Unexpectedly, the gross morphology of pituitaries from wild-type and Lym1heterozygous or homozygous mutant pituitaries did not reveal any obvious anatomical defect either in young mice (Figure 2A, E, I), or in older animals (Additional file 1: Figure S4). Expression of Pomc was assessed using ACTH immunofluorescence, and the differentiation status of corticotropes and melanotropes was assessed using immunostaining for Tpit (Tbx19) Differentiation of anterior lobe corticotropes and intermediate lobe melanotropes appeared normal in distribution and cell numbers (Figure 2C, G, K, S4) and expression of Pomc was not obviously affected by the Lym1 mutation (Figure 2B, F, G, S4). Histological analysis of adrenals from mice of the three genotypes also did not reveal any defect (Figure 2D, H, L). In separate experiments using expression array profiling, we have documented that both $N f k b 1$ and $N f k b 2$ are expressed in the adult mouse anterior pituitary (see Additional file 1: Figure S5).

NFkB2 is synthesized as a large precursor (p100) that must be processed to release the active $\mathrm{N}$-terminal rel- 


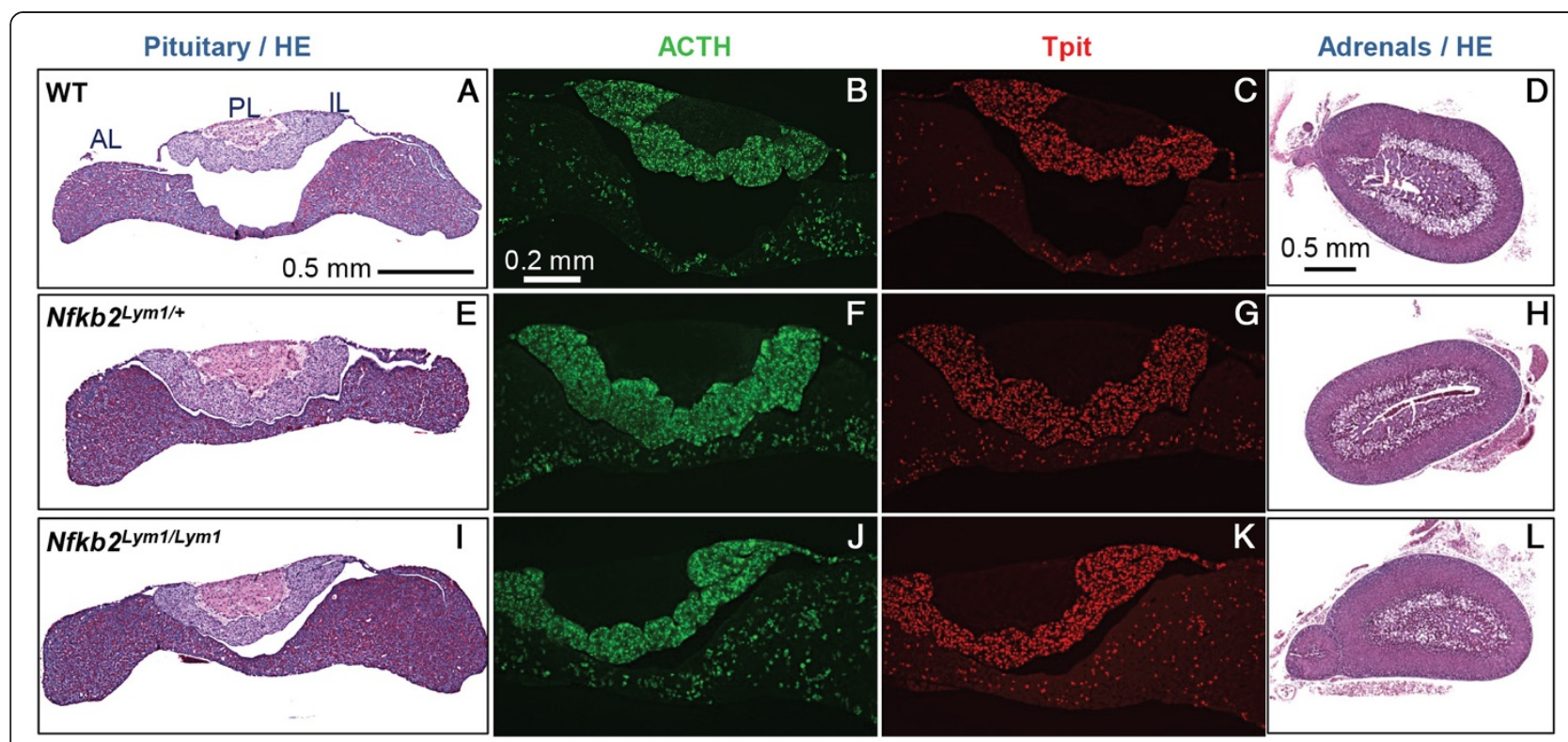

Figure 2 Histology of Lym 1 mutant mouse pituitaries and adrenals. HE staining of pituitaries (A, E, I) and adrenals (D, H, L) from WT (A, D), heterozygous (Nfkb2 $2^{L y m 1 /+}$ ) or homozygous (Nfkb2 $2^{L y m 1 / L y m 1}$ ) newborn mice. Staining of pituitaries with anti-ACTH (B, F, J) or anti-Tpit (C, G, K) antibodies in wild type, heterozygous, and homozygous mutant mice respectively. AL: anterior lobe, IL: intermediate lobe, PL: posterior lobe. Scale bars are shown.

homology domain (RHD, p52). Processing of NFkB2 is tightly regulated via the non-canonical pathway, with most protein remaining unprocessed until the cell receives an appropriate signal via receptors such as LT $\beta R$, BAFFR, RANK or CD40 [12,20,21]. Signalling leads to phosphorylation of specific serines near the C-terminus of NFKB2, including S866 and S870, via a pathway that employs the NIK and IKKA kinases [12]. This in turn leads to cleavage by the proteasome to produce the RHD p52 fragment. The occurrence of missense mutations bracketing S866 in two of our families suggests that these residues are important for recognition of the site by its kinase. Unprocessed full-length NFkB2 p100 can act as an IkB-like inhibitor [12,22]. Mutations in $N F K B 2$ leading to a protein that is unable to proceed via the non-canonical pathway, but is otherwise functional, are therefore anticipated to generate a dominant negative repressor, which could block the action of multiple RHD-dimers. The tight clustering of six different mutations in human DAVID syndrome patients in the region of NFKB2 regulated by the non-canonical pathway (Figure $1 \mathrm{E}$ ) is likely related to the specificity and rarity of the phenotype. It should be noted that mutations in NFKB2 have not been reported in cases of isolated anterior pituitary deficiency, lacking an immunodeficiency component.

The pathology we observed in the Lym1 mice is inconsistent with an effect of the $N k f b 2$ mutation in that strain at the level of primary pituitary development. Alternatively, the human endocrine phenotype might potentially result from an autoimmune reaction, consistent with the observed alopecia in several DAVID patients. $N f k b 2$ has been shown to play a role in acquired self-tolerance in knockout mice [23]. Mice accumulating p100 as a result of defects in or upstream of $N f k b 2$ show mild osteopetrosis, [19,24] and the RHD system is known to play a role in bone metabolism [25]. However, our DAVID syndrome patients carrying NFKB2 mutations have normal bone mineral density ( $\mathrm{T}$. Brue and M.-H. Quentien, pers. comm.).

The occurrence of GH and TSH deficiencies in our patient $\mathrm{C} 1$, as well as the abnormal pituitary anatomy observed in patients $\mathrm{B} 1$ and $\mathrm{D} 1$, constitute an expansion of the phenotype for this gene defect. We have previously reported that severe neonatal cortisol deficiency may be associated with transient GH deficiency [26] but an association with TSH deficiency is a novel observation. The subclinical phenotype of patient A5 is indicative of variable penetrance even in the same family, or a possibly delayed onset of the phenotype. The terminology of 'central adrenal' deficiency in other papers describing NFKB2 mutations may be overly restrictive, as the endocrine deficiencies among our patients are not restricted to hormones affecting adrenal function. A corticotropin-releasing factor test of patient D1 was consistent with a pituitary and not an hypothalamic defect.

We recently ascertained a fifth case (E1) with DAVID syndrome, in an unrelated French patient with both parents unaffected (but not sampled). Sanger sequencing of the two C-terminal coding exons of NFKB2 was negative for any variation. Thus the phenotype of this patient remains unexplained. 
A sixth, French-Canadian patient (F1), was ascertained after being hospitalized at age 17 years for a renal granuloma with immunoglobulin M-complex glomerulonephritis, low IgG levels, and a diagnosis of possible common variable immunodeficiency [27]. She was referred to Endocrinology due to primary amenorrhea and was found to have hypothalamic hypogonadism and severe ACTH and growth hormone deficiencies, although she was not of short stature [28]. Pituitary MRI showed a small anterior pituitary and a thin pituitary stalk with an ectopic posterior pituitary, suggesting a congenital defect [29]. Exome sequencing of DNA from this patient showed no pathogenic variants in $N F K B 2$, whereas all coding exons of the gene were well covered. As is typical, several hundred heterozygous rare potentially pathogenic variants were identified in the complete exome analysis of this patient. The results for patients E1 and F1 suggest that genetic heterogeneity is likely for DAVID syndrome, and that variable endocrine presentation may be a hallmark of the disorder.

The rel homology domain transcription factor signalling pathway is an active target of therapies for cancers especially breast and multiple myeloma [30,31]. Our results caution that broad inhibition of these pathways, or specific inhibition of NFKB2 processing, could have long-term deleterious effects on central endocrine function. Monitoring endocrine function may be indicated as a component of drug trials targeting NFkB pathways.

\section{Conclusions}

We confirm previous findings that mutations near the Cterminus of $N F K B 2$ cause combined endocrine and immunodeficiencies. De novo status of the mutations was confirmed in all cases for which both parents were available. The mutations are consistent with a dominant gainof-function effect, generating an unprocessed NFKB2 super-repressor protein. We expand the potential phenotype of such NFKB2 mutations to include additional pituitary hormone deficiencies as well as anatomical pituitary anomalies. The lack of an observable endocrine phenotype in Lym1 mice suggests that the endocrine component of DAVID syndrome is either not due to a direct role of NFKB pathways on pituitary development, or else that human and mouse pituitary development differ in its requirements for NFKB pathway function.

\section{Additional file}

Additional file 1: Clinical description of the patients.

\section{Competing interests}

The authors declare that they have no competing interests.

\section{Authors' contributions}

TB supervised clinical studies and participated in manuscript preparation.

$\mathrm{M}-\mathrm{HQ}$ assisted in clinical and molecular studies. KK performed mouse pathology studies. MB assisted in clinical studies. JC-C performed molecular sequencing. BD assisted with clinical studies. AB performed mouse pathology studies. CN performed technical work. DT Papadimitriou assisted with clinical studies. AP assisted with clinical studies. CH assisted with clinical studies. LP performed technical work. JS performed bioinformatic analyses. P-FS assisted with clinical studies. ST performed mouse pathology studies. AE supervised collection and handling of patient samples and participated in manuscript preparation. GW supervised clinical studies and participated in manuscript preparation. JM supervised bioinformatic analyses and participated in manuscript preparation. JD supervised mouse pathology studies and participated in manuscript preparation. MES supervised molecular studies and performed primary manuscript preparation. All authors read and approved the final manuscript.

\section{Acknowledgements}

First and foremost we thank the patients and their families for participating in this study. Thanks to Mauro Pocecco for providing clinical data on pedigree D and to Catherine Brue-Fabre for providing clinical data on pedigree E, to Cheri Deal, Johnny Deladoëy and Elie Haddad for valuable discussions. Thanks to the team at the Walter and Eliza Hall Institute for assistance in obtaining the Lym1 mouse strain. MES was supported by the Centre de Recherche du CHU Ste-Justine. All sequencing was performed at the McGill University and Genome Quebec Centre for Innovation. JD is supported by grants from the Canadian Institutes of Health Research (CIHR). The FORGE Canada Consortium: Finding of Rare Disease Genes in Canada; Steering Committee consists of Kym Boycott (leader; Ottawa, Ontario), Jan Friedman (co-leader; Vancouver, British Columbia), Jacques Michaud (co-leader; Montreal, Quebec), Francois Bernier (Calgary, Alberta), Michael Brudno (Toronto, Ontario), Bridget Fernandez (St Johns, Newfoundland), Bartha Knoppers (Montreal, Quebec), Mark Samuels (Montreal, Quebec), Steve Scherer (Toronto, Ontario). We also thank Janet Marcadier (Clinical Coordinator) and Chandree Beaulieu (Project Manager) for their contribution to the infrastructure of the FORGE Canada Consortium. FORGE was funded by the Government of Canada through the Canadian Institutes of Health Research (EAS), Genome Canada, Genome Quebec, Genome British Columbia and the Ontario Genomics Institute (OGI-049). This work was supported by the "Association pour le Développement de la Recherche Médicale au Centre Hospitalier Universitaire de Marseille" (ADEREM).

\section{Author details}

${ }^{1}$ Aix-Marseille University, Centre de Recherche en Neurobiologie et Neurophysiologie de Marseille (CRN2M), Centre National de la Recherche Scientifique, Unité Mixte de Recherche 7286, Faculté de Médecine de Marseille, 13344 Marseille, France. ${ }^{2}$ Assistance Publique-Hôpitaux de Marseille (APHM), Department of Endocrinology, Centre de Référence des Maladies Rares d'Origine Hypophysaire, Hôpital de la Timone, 13005 Marseille, France. ${ }^{3}$ Laboratoire de Génétique moléculaire, Institut de recherches cliniques de Montréal, 110 Avenue des Pins Ouest, Montréal, QC H2W 1R7, Canada. ${ }^{4}$ Ospedale Bufalini, Department of Paediatrics, Cesena, FC, Italy. ${ }^{5}$ Centre de Recherche du CHU Ste-Justine, 3175 Cote Ste-Catherine, Montreal, QC, Canada. ${ }^{6}$ Departments of Endocrinology and of Pediatrics, Centre Hospitalier Robert Debré, 51092 Reims, France. 7 Department of Pediatric-Adolescent Endocrinology and Diabetes, Athens Medical Center, Athens, Greece. ${ }^{8}$ Clinique universitaire de pédiatrie, CHU de Grenoble, Grenoble, France. ${ }^{9}$ Department of Human Genetics, McGill University, Montreal, QC, Canada.

${ }^{10}$ Endocrinology Service and Research Center, Department of Pediatrics, $\mathrm{CHU}$ Ste-Justine, University of Montreal, Montreal, QC, Canada. ${ }^{11}$ Department of Medicine, University of Montreal, Montreal, QC, Canada.

Received: 26 September 2014 Accepted: 11 December 2014 Published online: 19 December 2014

\section{References}

1. Quentien MH, Delemer B, Papadimitriou DT, Souchon PF, Jaussaud R, Pagnier A, Munzer M, Jullien N, Reynaud R, Galon-Faure N, Enjalbert A, Barlier A, Brue T: Deficit in anterior pituitary function and variable immune deficiency (DAVID) in children presenting with adrenocorticotropin deficiency and severe infections. J Clin Endocrinol Metab 2012, 97(1):E121-E128.

2. Younes JS, Secord EA: Panhypopituitarism in a child with common variable immunodeficiency. Ann Allergy Asthma Immunol 2002, 89(3):322-325. 
3. Tovo PA, Lala R, Martino S, Pastorelli G, De Sanctis C: Isolated adrenocorticotropic hormone deficiency associated with common variable immunodeficiency. Eur J Pediatr 1991, 150(6):400-402.

4. Chen K, Coonrod EM, Kumanovics A, Franks ZF, Durtschi JD, Margraf RL, Wu W, Heikal NM, Augustine NH, Ridge PG, Hill HR, Jorde LB, Weyrich AS, Zimmerman GA, Gundlapalli AV, Bohnsack JF, Voelkerding KV: Germline mutations in NFKB2 implicate the noncanonical NF-kappaB pathway in the pathogenesis of common variable immunodeficiency. Am J Hum Genet 2013, 93(5):812-824

5. Lee CE, Fulcher DA, Whittle B, Chand R, Fewings N, Field M, Andrews D, Goodnow CC, Cook MC: Autosomal-dominant B-cell deficiency with alopecia due to a mutation in NFKB2 that results in nonprocessable p100. Blood 2014 124(19):2964-2972.

6. Lindsley AW, Qian Y, Valencia CA, Shah K, Zhang K, Assa'ad A: Combined immune deficiency in a patient with a novel NFKB2 mutation. J Clin Immunol 2014, 34(8):910-915

7. Liu Y, Hanson S, Gurugama P, Jones A, Clark B, Ibrahim MA: Novel NFKB2 mutation in early-onset CVID. J Clin Immunol 2014, 34(6):686-690.

8. Majewski J, Schwartzentruber JA, Caqueret A, Patry L, Marcadier J, Fryns JP, Boycott KM, Ste-Marie LG, McKiernan FE, Marik I, Van Esch H, FORGE Canada Consortium, Michaud JL, Samuels ME: Mutations in NOTCH2 in families with Hajdu-Cheney syndrome. Hum Mutat 2011, 32(10):1114-1117.

9. Budry L, Balsalobre A, Gauthier Y, Khetchoumian K, L'Honore A, Vallette S, Brue T, Figarella-Branger D, Meij B, Drouin J: The selector gene Pax7 dictates alternate pituitary cell fates through its pioneer action on chromatin remodeling. Genes Dev 2012, 26(20):2299-2310.

10. Reynaud R, Gueydan M, Saveanu A, Vallette-Kasic S, Enjalbert A, Brue T, Barlier A: Genetic screening of combined pituitary hormone deficiency: experience in 195 patients. J Clin Endocrinol Metab 2006, 91(9):3329-3336.

11. Locatelli C, Lugaresi L, Zerial M, Bensa M, Pocecco M: Isolated adrenocorticotropic hormone deficiency in a child with common variable immunodeficiency. In European Society for Paediatric Endocrinology 45th Annual Meeting, Volume 65. Rotterdam: Hormone Research in Pediatrics; 2006:36.

12. Sun SC: The noncanonical NF-kappaB pathway. Immunol Rev 2012 246(1):125-140.

13. Xiao G, Harhaj EW, Sun SC: NF-kappaB-inducing kinase regulates the processing of NF-kappaB2 p100. Mol Cell 2001, 7(2):401-409.

14. Gloyn AL, Cummings EA, Edghill EL, Harries LW, Scott R, Costa T, Temple IK, Hattersley AT, Ellard S: Permanent neonatal diabetes due to paternal germline mosaicism for an activating mutation of the KCNJ11 Gene encoding the Kir6.2 subunit of the beta-cell potassium adenosine triphosphate channel. J Clin Endocrinol Metab 2004, 89(8):3932-3935.

15. Stoppa-Vaucher S, Ayabe T, Paquette J, Patey N, Francoeur D, Vuissoz JM, Deladoey J, Samuels ME, Ogata T, Deal CL: 46, XY gonadal dysgenesis: new SRY point mutation in two siblings with paternal germ line mosaicism. Clin Genet 2012, 82(6):505-513.

16. Gauthier J, Champagne $N$, Lafrenière RG, Xiong L, Spiegelman D, Brustein E, Lapointe M, Peng H, Côté M, Noreau A, Hamdan FF, Addington AM, Rapoport JL, Delisi LE, Krebs MO, Joober R, Fathalli F, Mouaffak F, Haghighi AP, Néri C, Dubé MP, Samuels ME, Marineau C, Stone EA, Awadalla P, Barker PA, Carbonetto S, Drapeau P, Rouleau GA, S2D Team: De novo mutations in the gene encoding the synaptic scaffolding protein SHANK3 in patients ascertained for schizophrenia. Proc Natl Acad Sci U S A 2010, 107(17):7863-7868.

17. Kara-Mostefa A, Raoul O, Lyonnet S, Amiel J, Munnich A, Vekemans M, Magnier S, Ossareh B, Bonnefont JP: Recurrent Williams-Beuren syndrome in a sibship suggestive of maternal germ-line mosaicism. Am J Hum Genet 1999, 64(5):1475-1478.

18. Rantamaki T, Kaitila I, Syvanen AC, Lukka M, Peltonen L: Recurrence of Marfan syndrome as a result of parental germ-line mosaicism for an FBN1 mutation. Am J Hum Genet 1999, 64(4):993-1001.

19. Tucker E, O'Donnell K, Fuchsberger M, Hilton AA, Metcalf D, Greig K, Sims NA, Quinn JM, Alexander WS, Hilton DJ, Kile BT, Tarlinton DM, Starr R: A novel mutation in the Nfkb2 gene generates an NF-kappa B2 "super repressor". $\mathrm{J}$ Immunol 2007, 179(11):7514-7522.

20. Mordmuller B, Krappmann D, Esen M, Wegener E, Scheidereit C: Lymphotoxin and lipopolysaccharide induce NF-kappaB-p52 generation by a cotranslational mechanism. EMBO Rep 2003, 4(1):82-87.

21. Dejardin E: The alternative NF-kappaB pathway from biochemistry to biology: pitfalls and promises for future drug development. Biochem Pharmacol 2006, 72(9):1161-1179.
22. Scheinman RI, Beg AA, Baldwin AS Jr: NF-kappa B p100 (Lyt-10) is a component of H2TF1 and can function as an I kappa B-like molecule. Mol Cell Biol 1993, 13(10):6089-6101.

23. Zhu M, Chin RK, Christiansen PA, Lo JC, Liu X, Ware C, Siebenlist U, Fu YX: NF-kappaB2 is required for the establishment of central tolerance through an Aire-dependent pathway. J Clin Invest 2006, 116(11):2964-2971.

24. Seo Y, Fukushima H, Maruyama T, Kuroishi KN, Osawa K, Nagano K, Aoki K, Weih F, Doi T, Zhang M, Ohya K, Katagiri T, Hosokawa R, Jimi E: Accumulation of p100, a precursor of NF-kappaB2, enhances osteoblastic differentiation in vitro and bone formation in vivo in aly/aly mice. Mol Endocrinol 2012, 26(3):414-422.

25. Boyce $B F$, Xing $L$, Franzoso $G$, Siebenlist $U$ : Required and nonessential functions of nuclear factor-kappa B in bone cells. Bone 1999, 25(1):137-139.

26. McEachern R, Drouin J, Metherell L, Huot C, Van Vliet G, Deal C: Severe cortisol deficiency associated with reversible growth hormone deficiency in two infants: what is the link? J Clin Endocrinol Metab 2011, 96(9):2670-2674.

27. Benoit G, Lapeyraque AL, Sartelet H, Saint-Cyr C, Le Deist F, Haddad E: Renal granuloma and immunoglobulin M-complex glomerulonephritis: a case of common variable immunodeficiency? Pediatr Nephrol 2009, 24(3):601-604.

28. Hasselmann C, Samuels ME, Van Vliet G: Goliath, a Variant of DAVID Syndrome? In 53rd Annual Meeting of the European Society of Pediatric Endocrinology. Dublin: European Society of Pediatric Endocrinology; 2014:283.

29. Deal C, Hasselmann C, Pfaffle RW, Zimmermann AG, Quigley CA, Child CJ, Shavrikova EP, Cutler GB Jr, Blum WF: Associations between pituitary imaging abnormalities and clinical and biochemical phenotypes in children with congenital growth hormone deficiency: data from an international observational study. Horm Res Paediatr 2013, 79(5):283-292.

30. Xiao G, Rabson AB, Young W, Qing G, Qu Z: Alternative pathways of NFkappaB activation: a double-edged sword in health and disease. Cytokine Growth Factor Rev 2006, 17(4):281-293.

31. Baud V, Karin M: Is NF-kappaB a good target for cancer therapy? Hopes and pitfalls. Nat Rev Drug Discov 2009, 8(1):33-40.

\section{Submit your next manuscript to BioMed Central and take full advantage of:}

- Convenient online submission

- Thorough peer review

- No space constraints or color figure charges

- Immediate publication on acceptance

- Inclusion in PubMed, CAS, Scopus and Google Scholar

- Research which is freely available for redistribution

Submit your manuscript at www.biomedcentral.com/submit
C Biomed Central 